\title{
El rol de la Investigación clínica frente a la epidemia del COVID-19 en el Perú
}

\section{The role of clinical research in the Peruvian context of COVID-19 epidemic}

\author{
Alonso Soto ${ }^{\prime}$
}

La pandemia del COVID 19 ha generado una crisis no solo desde el ámbito médico sino económico y social. Para el 7 de abril del 2020 se han confirmado cerca de 1,3 millones de casos a nivel mundial con 72614 víctimas; y, en el Perú, se han verificado 2954 casos y registrado 107 fallecidos. $(1,2)$

Afrontar la pandemia debe involucrar decisiones basadas en la mejor información disponible. La investigación es así una herramienta fundamental para la toma de decisiones a fin de reducir el contagio, garantizar un diagnóstico oportuno y el mejor tratamiento posible. Sin embargo, la pandemia exige respuestas rápidas y el proceso de investigación debe adaptarse para ser capaz de plantear dichas respuestas con la celeridad que la emergencia lo requiere. La comunidad científica debe desarrollar un rol activo en la solución de nuestros problemas y no esperar pasivamente las respuestas de estudios extranjeros. Aunque la pandemia es global, el éxito de la respuesta a la misma depende de la respuesta local. Las sociedades científicas tienen un rol importante no solo en brindar guías para el manejo de los pacientes sino además en identificar las áreas de incertidumbre y promover la investigación operativa.

La Organización Mundial de la Salud (OMS) ha definido áreas de acción en investigación inmediata, las que deben guiar el proceso en cada país (Tabla 1). (3) Aunque en adelante nos enfocaremos en la necesidad de investigación clínica, la investigación es necesaria en una serie de otros campos relevantes incluyendo estudios de ciencias básicas, epidemiológicos, de pruebas diagnósticas e intervenciones comunitarias a gran escala.

I Médico internista. MSc Clinical Trials. PhD Health Sciences. Instituto de Investigación en Ciencias Biomédicas, Universidad Ricardo Palma. Departamento de Medicina, Hospital Nacional Hipólito Unanue, Lima.
Soto A. El rol de la Investigación clínica frente a la epidemia del COVID-19 en el Perú. 2019;33(I):12-14.

https://doi.org/10.36393/spmi.v33i1.505

A continuación, presentaremos una lista (no exhaustiva y reconociendo los sesgos propios del autor) de aspectos enfocados en la investigación clínica en los que consideramos se requiere acción de manera urgente y coordinada, en la que el apoyo del del internista será especialmente relevante para el escenario peruano.

Investigación en el uso de drogas activas frente al SARS$\mathrm{CoV}-2$

Lamentablemente, hasta el momento no se dispone de ningún tratamiento que haya demostrado efectividad para el COVID-19. Sin embargo, muchos clínicos parecen estar convencido del beneficio de algunos tratamientos los cuales aún no tienen un respaldo sólido para su prescripción. Las guías de los Centers for Disease Control and Prevention (CDC), de los EE.UU., no sugieren ningún fármaco específico para el COVID-19 más allá del cuidado de soporte, al igual que las guías del Survival Sepsis Campaign. $(4,5)$

Existen diversos reportes sobre agentes promisorios. Es por ello necesario el desarrollo de ensayos clínicos rápidos para comparar el uso de estas terapias y definir su utilidad real. La OMS ha lanzado la iniciativa SOLIDARITY la cual incluye la realización de un megaensayo clínico comparando hidroxicloroquina (o cloroquina); lopinavir/ ritonavir asociado o no a interferón beta- $1 \mathrm{~b}$ y remdesivir. (6) Hasta el momento, son 70 países, incluido el Perú, que han confirmado su participación en el ensayo, el cual brindará respuestas rápidas con respecto a la efectividad de estos tratamientos. Adicionalmente, existen actualmente más de 700 ensayos clínicos registrados relacionados a COVID -19 en el registro internacional de ensayos clínicos de la OMS. (7)

Recientemente, se han planteado tratamientos que podrían actuar frente al componente inflamatorio de la enfermedad 
I. Investigación en el desarrollo de herramientas de diagnóstico en el punto de atención ("point of care"). La disponibilidad de estas herramientas es fundamental para la identificación inmediata de identificar y tratar enfermos y evaluar la diseminación del virus.

2. Evaluación inmediata de los datos ya disponibles para optimizar el cuidado estándar de los pacientes en los diferentes estadios de la enfermedad.

3.Evaluación inmediata del efecto de terapias adyuvantes y de soporte incluyendo por ejemplo el uso de esteroides y oxígeno de alto flujo

\section{Optimización del uso de Equipo de Protección Personal y otras medidas de prevención y control de la infección en los establecimientos de salud y la comunidad}

\section{Evaluar toda la evidencia disponible para la} identificación de hospederos animales del virus

6.Acelerar la evaluación de tratamientos y vacunas a través del desarrollo rápido de "protocolos maestros" para ensayos clínicos que permitan identificar qué funciona y qué no, la colaboración multicéntrica y la evaluación expeditiva por comités de ética

\section{Mantener un alto grado de comunicación e} interacción con las fuentes de financiamiento para garantizar la implementación de investigación prioritaria.

\section{Compartir de manera amplia y rápida muestras} clínicas, estudios de caracterización del virus y datos para propósitos inmediatos de salud pública. Los productos o innovaciones resultantes deben ser igualmente compartidos en forma justa y equitativa denominado "tormenta de citokinas", incluyendo fármacos anti interleukina-6 como el tocilizumab o dosis altas de corticoides. El uso de estos agentes debe evaluarse en ensayos clínicos auspiciados por el Ministerio de Salud (MINSA) con la colaboración de las sociedades científicas. Los ensayos clínicos podrían parecer utópicos en este contexto, pero los ensayos pragmáticos (probablemente de naturaleza abierta) no solo son viables sino son un imperativo para el país. Más aun, dada la situación de emergencia, el Instituto Nacional de Salud está llevando a cabo de manera expeditiva la evaluación de los ensayos para COVID-19 lo que facilitará su pronta ejecución. Aun en el caso de no poder realizarse estos ensayos, existen alternativas como estudios de intervención no aleatorizados o cuasi experimentales en los que se comparen los desenlaces antes y después de introducir un tratamiento. Finalmente, es importante sistematizar la experiencia ganada a través de estudios de cohorte e inclusive series de casos que nos permitan evaluar la respuesta a los tratamientos ensayados, identificar las características de nuestros pacientes, sus desenlaces y factores pronósticos. Todos ellos deben ser publicado a fin de ser ampliamente difundido entre los colegas responsables de la atención de los pacientes afectados. Actualmente, muchas revistas biomédicas ofrecen un proceso de revisión rápida que permitirá la diseminación pronta de los resultados. Es un deber de la comunidad científica que las experiencias ganadas en el manejo de los pacientes no queden sólo en el médico tratante.

Estudios enfocados en el personal sanitario y grupos de alto riesgo

El personal sanitario constituye una prioridad dado que no solo son un grupo de alto riesgo sino además son quienes brindan la atención directa al paciente. El desarrollar intervenciones que permitan reducir la probabilidad de contagio es una línea de investigación importante. Se ha planteado el uso de "quimioprofilaxis" con hidroxicloroquina en el personal de salud y pacientes de alto riesgo y actualmente la India recomienda el uso profiláctico de hidroxicloroquina en forma semanal para trabajadores de salud que atienden COVID-19 y contactos asintomáticos de pacientes con infección demostrada. (8) La eficacia y seguridad de esta aproximación debe ser evaluada. El MINSA debería promover la realización de estos ensayos o, de nos ser posible, al menos estudios comparativos abiertos no aleatorios o de cohortes clínicas. Como línea de investigación adicional se debería investigar el tratamiento en adultos mayores con enfermedad leve. Estudios de epidemiología hospitalaria y valoración de reglas de predicción clínica

El conocimiento de la epidemiología hospitalaria, incluyendo las características clínicas de los pacientes hospitalizados, la frecuencia y progresión a formas 
graves debe analizarse rápidamente y generar reportes que permitan conocer nuestra casuística y guiar el manejo de los clínicos involucrados en el manejo de este nuevo reto clínico. En tal sentido es importante la colaboración formal de universidades, sociedades científicas y otros grupos de investigación con el MINSA para la producción de publicaciones científicas rigurosas, pero rápidas y periódicas. La disposición de repositorios de datos abiertos es una alternativa que el MINSA debe considerar.

Asimismo, es importante conocer los predictores de mortalidad y desenlaces desfavorables en los pacientes infectados. Ello tiene incidencia directa en la decisión de hospitalización, decisiones terapéuticas y eventualmente en la decisión de someter a terapias invasivas. La validación de reglas de predicción clínica como NEWS (9) o Brescia es prioritaria.

\section{Coinfección con otros virus y bacterias}

La sobreinfección bacteriana es una importante causa de muerte y complicaciones en infección virales respiratorias, particularmente en casos de influenza donde las infecciones neumocócicas y estafilocócicas son responsables de la mayor parte de muertes. La contribución de estas sobreinfecciones a la mortalidad y complicaciones en COVID-19 es desconocida y la investigación al respecto prioritaria.

En suma, la investigación es un componente fundamental para la toma de decisiones y en particular la investigación en drogas con acción contra el SARS-CoV-2 es prioritaria dado que aún no existen terapias farmacológicas que hayan demostrado beneficio en pacientes con COVID-19. Aunque el entusiasmo y el deseo de ayudar al paciente hacen que cada nueva terapia existente sea rápidamente incorporada, es una necesidad ética y moral el desarrollar estudios comparativos que permitan identificar las mejores intervenciones terapéuticas. En caso esto no sea posible, todo tratamiento sin eficacia demostrada debe contar con la anuencia del paciente y ser registrada a efectos de ser sistematizada y rápidamente analizada. Debemos consolidar urgentemente la información ya existente para caracterizar a los pacientes e identificar los factores asociados a desenlaces desfavorables en nuestra población. El COVID-19 es una condición nueva y la única manera de aprender de ella es a través de la investigación coordinada y multidisciplinaria. La necesidad de una agenda nacional de investigación en COVID-19 es una prioridad que deben asumir conjuntamente el gobierno y las instituciones científicas y académicas.

\section{REFERENCIAS BIBLIOGRÁFICAS}

I. World Health Organization. Coronavirus disease 2019 (COVID-19) Situation Report-78. URL disponible en https://www.who.int/docs/ default-source/coronaviruse/situation-reports/20200407-sitrep-78covid-19.pdf?sfvrsn=bc43elb_2 (Fecha de acceso: 7/4/2020).

2. Ministerio de Salud. Sala situacional COVID-19. URL disponible en https://covid 19.minsa.gob.pe/sala_situacional.asp (Fecha de acceso: 7/4/2020).

3. World Health Organization. A coordinated global research roadmap: 2019 novel Coronavirus. URL disponible en https://www. who.int/blueprint/priority-diseases/key-action/Coronavirus_ Roadmap_V9.pdf?ua=I (Fecha de acceso: 7/4/2020).

4. Centers for disease control.Interim clinical guidance for management of patients with confirmed coronavirus disease (COVID-I9). URL disponible en https://www.cdc.gov/coronavirus/2019-ncov/hcp/ clinical-guidance-management-patients.html\#Sepsis

5. Ihazzani W, Hylander M, Arabi YM; Loeb M, Ng M, Fan E, et al. Surviving Sepsis Campaign: Guidelines on the management of critically ill adults with coronavirus disease 2019 (COVID-19). Intensive Care Med. URL disponible en https://link.springer.com/ content/pdf//0.1007/s00134-020-06022-5.pdf (Fecha de acceso: 6/4/2020).

6. World Health Organization. "Solidarity" clinical trial for COVID-19 treatments. URL disponible en https://www.who.int/emergencies/ diseases/novel-coronavirus-2019/global-research-on-novelcoronavirus-2019-ncov/solidarity-clinical-trial-for-covid- 9 treatments (Fecha de acceso: 6/04/2020).

7. World Health Organization. International Clinical Trials Register (ICTR). URL disponible en https://www.who.int/ictrp/en/ (Fecha de acceso: 6/04/2020).

8. Indian Council of Medical Research. The use of Hydroxychloroquin as prophylaxis for SARSCoV2 infection. URL disponible en https:// www.mohfw.gov.in/pdf ryontheuseofHydroxychloroquinasprophy laxisforSARSCoV2infection.pdf (Fecha de acceso: 6/4/2020).

9. Royal College of physicians NEWS National Early Warning Score (NEWS2). URL disponible en https://www.rcplondon.ac.uk/ projects/outputs/national-early-warning-score-news-2 (Fecha de acceso: 7/04/2020).

\section{CORRESPONDENCIA}

sotosolari@gmail.com 